\title{
Operationalizing Sustainable Development, Stakeholder Theory, Corporate Social Responsibility to Improve Community Engagement Outcomes
}

\author{
Jerold Edson Ring ${ }^{1}$ \\ ${ }^{1}$ University of Phoenix, School of Advanced Studies, Phoenix, Arizona USA \\ Correspondence: Jerold E. Ring, School of Advanced Studies, University of Phoenix, 4035 South Riverpoint \\ Parkway, Phoenix, AZ 85040-0723, USA. Tel: 602-557-2519. E-mail: jring1@email.phoenix.edu
}

Received: October 11, 2021

Accepted: November 18, 2021

Online Published: November 27, 2021

doi:10.5539/jsd.v15n1p1

URL: https://doi.org/10.5539/jsd.v15n1p1

\begin{abstract}
Businesses fail in the absence of an engagement strategy with stakeholders who influence and are influenced by a company's business activity in communities where the company has a presence. A lack of understanding of the interdependency implicit in the company/community relationship, and the absence of new frameworks to encourage collaboration, has led increasingly to an inability to resolve conflicting views. An evolving approach is business participation in multisector collaborative watershed initiative partnerships. This qualitative multiple case study examines the perspectives of 22 participants of two watershed partnerships relating to corporate social responsibility (CSR), the Triple Bottom Line of sustainable development (TBL), and shared value. The study's theoretical framework focuses on stakeholder theory integrated with the corporate imperatives of CSR, the TBL, and shared value. The research question is how these constructs might define an unexplored community engagement framework between the company, the community, and watershed initiatives. The research data suggests these factors are interrelated, and, when integrated into a strategy, define a Sustainable Community Engagement Framework that redefines the business case for engaging stakeholders to help resolve often conflicting views relating to the company's business activity. The study outcomes are particularly relevant to academics, practitioners, business managers, and consultants engaged with high profile organizations such as chemical, petroleum and utility businesses whose presence may generate community concerns about their business activities, especially their environmental footprint.
\end{abstract}

Keywords: community engagement framework, conflicting stakeholder views, corporate social responsibility, multisector collaborative watershed initiative partnerships, shared value, stakeholder engagement, sustainable communities, Triple Bottom Line of sustainable development

\section{Introduction}

The generally accepted role of business in society has been to research and produce useful products that improve quality of life while making a profit and earning the support of the community in which the business is engaged (FitzGerald \& Cormack, 2006; Krishnan, 2011; Williams, 2014). However, the relationship between business and society has come under increasing scrutiny because of concern about the unrestrained growth of business' influence in the evolving global economy (Nemetz, 2015). Further, a lack of understanding has become more commonplace relating to the interdependency implicit in the relationship between the company and community stakeholders; often, the result is an inability to resolve conflicting views (Dunham, Freeman, \& Liedtka, 2006; McLennan \& Banks, 2019). This is an alarming trend because businesses have failed in the absence of sustainable relationships with individuals, organizations, and groups affected by the company's business activity in communities where the company is located (Dunham et al., 2006).

Reducing stakeholder conflict will require developing innovative dialogue processes that expand management thinking beyond traditional engagement processes (Burchell \& Cook, 2013). A strategy that is gaining acceptance is to generate shared value for the company and the community by applying the construct of the Triple Bottom Line (TBL) of sustainable development to the firm's corporate social responsibility (CSR) engagement practices (Porter \& Kramer, 2011). In fact, there is increasing support for the idea that developing new frameworks for engaging stakeholders that integrate the principle of shared value to help resolve conflicting stakeholder views is 
essential to future business success (Harrison, 2013).

Issues least understood are the intention of the company, to whom the company is responsible, and the degree to which the company and the community are mutually accountable to achieve business and community success (Bowie, 2012; Dunham et al., 2006; McLennan \& Banks, 2019).

An encouraging approach that has potential for reducing stakeholder conflict is business participation in collaborative watershed initiative partnerships that address community quality of life issues (Bradley, Hauser, Koontz, \& Bruskotter, 2012). Collaborative watershed initiative partnerships are multisector groups that work together informally to address environmental issues within the boundary of a watershed (Benson, Jordan, Cook, \& Smith, 2013; Brinkman, Seekamp, Davenport, \& Brehm, 2012; Leach \& Pelkey, 2001). Watershed initiative partnerships often focus on integrating community economic, social, and environmental resources (Genskow, 2009). Companies that pursue innovative engagement strategies to resolve stakeholder differences such as with U.S. watershed initiatives may achieve competitive advantage as well as contribute to improved community quality of life economically, socially, and environmentally (Dawkins, 2014; Hall \& Jeanneret, 2015).

\section{Gap in Current Scholarly Thinking}

The purpose of business is often controversial given that society is continuously reshaping business expectations including what business activities are acceptable (Cramer, 2002; Crane, Palazzo, Spence, \& Matten, 2014). Theorists continue to debate how to integrate the agenda of the firm with the agenda of society (Chong, 2013; Devenin \& Bianchi, 2018). A trend gaining momentum is realignment of citizenship programs from one size fits all philanthropy to programs aligned with the company's core business purpose including accountability for economic, environmental, and social issues (Warhurst, 2005). Even so, it is also clear that shared value and application of the TBL of sustainable development to CSR engagement initiatives are not well understood (Rangan, Chase, \& Karim, 2015).

Stakeholder theory emerged in the early 1900's as a counter argument to the assertion that business must act in the interests of shareholders (Sonpar, 2011). Stakeholder research in the next thirty years must focus on improving understanding of how stakeholder theory creates value (Parmar, Freeman, Harrison, Wicks, Purnell, \& deColle, 2010). Clarity is required relating to stakeholder best practices, particularly understanding how and why they create value and how and why engagement strategies change over time (Parmar et al., 2010). Multiple literature sources support Sloan's (2009) assertion the engagement strategy of the future will be characterized by collaboration, learning, innovation, and a transformational mindset within the business sector.

Without question, CSR thought is evolving from whether and how to how well CSR is adding value to the business ("Does CSR Work?" 2008). In addition, there is increasing empirical support for the assertion that grassroots watershed initiatives are effective at building trust and social capital because stakeholders who participate are often a reflection of the community.

Considerable scholarly support exists for Burchell and Cook's (2013) conclusion that new engagement frameworks are required that facilitate resolution of conflicting expectations among groups and individuals who influence or who might influence a company's business practices. Multiple literature citations support Harrison's (2013) belief that creating frameworks for engaging stakeholders and understanding the value created is essential to future business success.

Given these assertions, and, in agreement with Bowen, Newenham-Kahindi, \& Herremans, (2010), there is clearly a gap in scholarly thinking relating to the need for new engagement frameworks, what community engagement strategies are appropriate, when to apply them, and how to define the benefits.

\section{Research Question}

The specific problem addressed by this qualitative, multiple case study is the lack of an existing framework regarding the creation of shared value when applying the TBL of sustainable development to CSR engagement initiatives among the company, the community, and U.S. watershed initiatives. The study purpose is to investigate factors that define a framework regarding the creation of shared value when applying the TBL as a CSR strategy between the company, the community, and U.S. watershed initiatives. The study focus is to compare shared value, CSR, and the TBL perspectives of leaders and participants from two collaborative watershed initiative partnerships. The research question is: How do shared value, CSR, the TBL define an engagement framework between the company, the community, and U.S. watershed initiatives to help resolve often conflicting stakeholder' views?

\section{Theoretical Framework}

The theoretical framework for this study is stakeholder theory integrated with the corporate imperatives of CSR, 
the TBL, and shared value. Stakeholder theory focuses on how business interacts with society with emphasis on processes that address conflicting expectations. The role of business is to integrate economic resources, political support, and knowledge generating technology to meet stakeholder interests as well as develop competitive advantage (Krstovic, Bakic, \& Kostic, 2012). According to Harrison and Wicks (2013), stakeholder theory focuses on how business interacts with society with emphasis on processes that address conflicting expectations. The stakeholder concept addresses a theoretical view that the social mission of business is to enhance the firm's profitability (Harrison \& Wicks, 2013). Systems theorists and organization theorists focus on the construct of organizations as open systems that connect with external individuals and groups by employing strategies that integrate their interests (Emerson et al., 2011).

Bowie (2012) noted the emergence of two strategic questions: What is the intention of the firm and to whom is the firm responsible? Brown and Forster (2013) maintain CSR, broadly defined as business's obligations to society, is the focus of scholars to improve understanding of the interdependency between the firm and stakeholders particularly communities. Four dimensions of CSR are to enhance profitability, be socially responsible, expand the business's products and services, and embrace ethical practices (Brown \& Forster, 2013). Managers struggle to determine the meaning, and value of CSR because of a lack of consensus about the meaning of the term (Madrakhimova, 2013; Nwagbara \& Reid, 2013). Moratis (2014) suggested CSR was a legitimate academic pursuit that included instrumental, political, and ethical approaches such as the TBL and shared value. Applied to the firm, sustainable development requires integration of the TBL of economic prosperity, social equity, and environmental quality in strategic decision-making; however, the three dimensions are not always in harmony (Gao \& Zhang, 2006; Glavas \& Mish, 2015; Gomis et al. 2011). In the view of Tideman, Arts and Zandee (2013), the problem is often uncertainty and disagreement about the TBL response required.

Theorists continue to debate how to integrate the agenda of the firm with the agenda of society (Chong, 2013). Porter and Kramer (2011) argue the solution is to redefine the purpose of the firm by adopting the principle of shared value as creating economic value for the firm in a manner that also creates value consistent with the interests of society. Shared value is not corporate responsibility, or philanthropy (Porter \& Kramer, 2011). In Porter and Kramer's view, the firm gains competitive advantage by aligning the firm's business purpose with quality-of-life issues that need improvement in communities where the firm conducts business. Strand, Freeman, and Hockerts (2015) contend shared value is a restatement of stakeholder theory. Rangan et al. (2015) found that despite the widespread acceptance of the principle of shared value, there is little evidence to support its use in actual practice.

Theorists, on the other hand, argue investing in social capital is a potential corporate strategy to improve the engagement practices between business and society (Spence \& Schmidpeter, 2003). Social capital is good will that is generated from the network of relationships maintained by an individual or social organization (Adler \& Kwon, 2002; Liu, Eng, \& Ko, 2013). Understanding the synergy between stakeholder theory and social capital theory is critical for learning how to develop productive stakeholder relationships in the global economy of the 21 st century (Cots, 2011). Engagement strategies, partnerships, and community initiatives influence the firm's license to operate, development of social capital, as well as encourage innovative problem solving for the firm and the community (Russo \& Perrini, 2010; Perrini, Russo, Tencati, \& Vurro, 2011). Cots (2011) argues stakeholder social capital encourages productive firm- stakeholder relationships because trust and a willingness to work together defeats mistrust and unresolvable conflict.

A related issue is the need to improve understanding of contextual factors that influence the success of engagement practices such as industry, location, and community values, norms, and culture (Devenin \& Bianchi, 2018; Sloan, 2009). At the macro level, the level of transparency of a company's corporate social disclosures are related to the variety of cultures and social orientation of the countries where a company has a presence (Orij, 2010). In agreement with Orij (2010), Vitolla, Raimo, Rubino, \& Garzoni (2019) acknowledged the role of culture as a determinant of the quality of integrated reporting with emphasis on cultural systems that value sustainability issues, ethics, and good governance. In a separate study, the quality of integrated reporting was positively associated with stakeholder pressure from customers, environmentalists, employees, shareholders, and government (Vitolla et al., 2019). Chiu \& Wang (2015) found the quality of a company's social reporting intended to earn stakeholder support is influenced by the importance the company attaches to its stakeholders, the degree to which a country's local, and national regulations are enforced, global supply chain issues, and international capital market expectations.

\section{Methods}

The research design is a qualitative, multiple case study. The most defining characteristic of a case study is the boundaries or limits of the study content (Toma, 2011). The bounded description for this study is the creation of shared value when applying the TBL of sustainable development to CSR engagement initiatives to define an 
unexplored framework for a community engagement strategy between the firm, the community, and U.S. watersheds. The desired outcome is to help resolve often conflicting stakeholder views. The case study design is appropriate because the study intent is not to develop theory, explore the life of an individual, investigate a culture, or examine experiences individuals have in common. Rather, the intent is to explore a bounded, real-life situation, what Stake (1995) and Yin (2014) maintain is the purpose of a case study.

\subsection{Study Focus}

The primary study focus is to compare shared value, CSR, and the TBL perspectives of leaders and participants from two collaborative watershed initiative partnerships. A second study focus is to examine whether the study findings support an emerging view in the literature that stakeholder theory addresses stakeholder differences by pinpointing relationships that seek common ground through collaboration (Burchell \& Cook, 2013; Harrison \& Wicks, 2013; Sloan, 2009; Steurer, 2006). Additionally, the learning from the study findings might identify a combination of TBL related factors that could be useful to communities that give priority to improving their quality of life economically, socially, and environmentally.

Yin (2014) maintained case studies were not samples because their numbers were too small to represent a larger population. Rather, Yin believed the focus of the case study should be on collaborating, modifying, or rejecting the theoretical concepts that were part of the study research design. Selection of two watershed focused organizations was justified by a general guideline of qualitative research that suggests collection of extensive data from a few individuals and organizations is appropriate because they are positioned to contribute to an in-depth understanding of the research problem (Padgett, 2012).

\subsection{Study Design}

The plan for this study was a purposive sample design. Individuals who participated in U.S. watershed initiatives were the total study population. The target population was individuals who were leaders and participants in the two watershed organizations that are the focus of the study. The study sample was the individuals who agreed to be interviewed.

Dabic and Stojanov (2014) determined the most valuable data from qualitative research is a limited number of individuals with first-hand knowledge of the study problem using semi-structured interviews. Twenty-two participants from two watershed organizations in one mid-Eastern state agreed to semi-structured interviews. The study participants had personal knowledge of the factors that might define an unexplored community engagement framework between the firm and the community applicable to U.S. watershed initiatives. These individuals were most relevant to the study because they are directly involved in decisions relating to the management processes, organization design, and funding of projects and, therefore, they had the most experience, knowledge, and insight relating to the study research questions.

The executive directors of both organizations recommended specific individuals be interviewed from their organizations. The primary inclusion criterion was to identify at least one interviewee from each sector of the organization such as business, funders, and nongovernment organizations (NGO's) who had experience, knowledge, and insight relating to the study objectives. The primary exclusion criterion was a lack of personal knowledge about the study objectives. At least one individual with knowledge of the study research questions participated from each organization's primary sectors to assure diversity of thought regarding the study research questions. This approach to identifying participants is consistent with the purposive sampling method. In purposive sampling, individuals participate for a purpose such as being representative of a group that has diverse views of an issue (Golafshani, 2003).

All interviews were recorded and then transcribed. A verbatim transcript was a requirement for proper coding of interview content into categories that help define data patterns important to proper data analysis (Leedy \& Ormrod, 2016). The transcriptions were uploaded to NVivo11 software for analysis and theme development. NVivo11 software also helped identify emerging patterns and ideas. Codes categorized interview responses into themes, relationships, and patterns for each of the cases. Matching the coded data from the study with relevant text containing words and phrases from the theoretical constructs, conceptual framework, and applicable passages in the literature defined themes leading to the development of appropriate conclusions (Salmona \& Kaczynski, 2016).

\subsection{Reliability, Validity, Data Saturation}

In Howell's (2013) view, reliability and validity were inseparable - a concept is not valid unless it is reliable. Shank (2006) maintained reliability is about the accuracy of measurements while validity is about the truth of observations. Credibility occurs when study participants and uninvolved researchers agree the description and findings of a case are an accurate representation of reality (Padgett, 2012). Jensen and Sandstrom (2013) suggest 
methods that increase credibility are: (a) allow enough time with participants to assure accuracy of their views; (b) use a holistic approach to interpreting data such as triangulation; (c) ask peers to critique findings, and (d) request participant' review of the study data analysis. These methods were implemented except for participant review of study data analysis. The knowledge, and experience of the executive directors who reviewed the study findings, conclusions, and recommendations was determined to be a credible link between the responses of the participants and the themes and codes that emerged to help assure study' credibility.

Data saturation occurs when no new themes or content emerges from data gathering methods (Fusch \& Ness, 2015). Interviews and document reviews continued until the appropriate degree of trustworthiness occurred based on repetitive data (Toma, 2011). Data saturation occurred at the completion of 22 interviews. The $22^{\text {nd }}$ interview consisted of responses to the interview questions that were close to responses from the previous five interviews.

\subsection{Triangulation}

Triangulation is the comparison of data from multiple sources to develop an in-depth knowledge of a situation, experience, or phenomena (Barnham, 2015; Carter, Bryant-Lukosius, Neville, \& DiCenso, 2014; Padgett, 2012). Barnham (2015) concluded multiple triangulation methods are a legitimate response to criticism that case study research lacks the rigor of quantitative research. Fusch and Ness (2015) agreed triangulation is a key advantage of the case study design. Semi-structured interviews, public document review, meeting attendance, and observations were used to triangulate the study data. When triangulated, the perspectives of the leaders and participants of the two watershed organizations represented a diverse set of data.

\section{Findings}

Scholarly literature does not adequately address shared value and the application of the TBL of sustainable development to CSR engagement initiatives (Porter \& Kramer, 2011; Rangan et al., 2015). The general problem is insufficient understanding of how shared value is created between the firm and the community (Porter \& Kramer, 2011). The specific problem is the lack of an existing framework relating to the creation of shared value when applying the TBL of sustainable development to CSR engagement initiatives between the firm, the community, and U.S. watershed initiatives to help resolve often conflicting stakeholder views. Issues least understood are the intention of the firm, to whom is the firm responsible, and the degree to which the firm and the community are mutually accountable to achieve business and community success (Bowie, 2012; Dunham et al., 2006).

The research question (RQ) was: How do shared value, CSR, TBL define a community engagement framework between the firm, the community, and U.S. watershed initiatives to help resolve often conflicting stakeholder views? Themes and subthemes were developed to answer the research question, and four research sub-questions (SQ). The four sub-themes supported the key theme.

1) RQ. Key Theme: Shared value, CSR, TBL were factors that defined a community engagement framework when integrated into a single strategy between the firm, the community, and U.S. watershed initiatives using a dialogue process to help resolve often conflicting stakeholder views.

This theme was one of two primary outcomes of the study findings supported by the data analysis of 22 interviews of individuals who participated in the two watershed initiatives selected for study and the analysis of the responses from the four research sub-questions (SQ 1-4). The theme confirmed shared value, CSR, and TBL defined a community engagement framework between the firm, the community, and U.S. watershed initiatives. The key theme addressed the gap in the literature discussed by Dunham, Freeman and Liedtka (2006) regarding the inadequacy of innovative community engagement frameworks that explore new combinations of factors that facilitate the relationship between the firm and the community. The key theme was an example of an emerging approach to generate shared value for the firm and the community by applying the shared value construct to the firm's engagement practices (Porter \& Kramer, 2011). An example of shared value that aligned with the key theme was the TBL drives improvements in community economic prosperity, social equity, and environmental quality (Rangan, Chase, \& Karim, 2015).

2) SQ1. Subtheme: The factors that contributed to creating shared value were interrelated and contributed to creating shared value when joined together in a Sustainable Community Engagement Framework (Appendix A) to help resolve often conflicting stakeholder views. The factors defined from analysis of the study interview data were: sense of place, moral compass, collaborative approach, CSR, TBL, and license to operate. This subtheme answered how of the research question by documenting the factors that contributed to creating shared value were interrelated and may create shared value when joined together in a strategy to help resolve stakeholder differences. The insight was the factors that contributed to creating shared value were more inclusive of how shared value was created than the basic framework described in the Key Theme. The inclusion of the TBL as a factor suggested the framework 
should be characterized as sustainable. The Sustainable Community Engagement Framework (Appendix A) was the second primary outcome of this study and a direct, documented response to the How of the research question. This outcome further addressed the gap in the literature discussed by Dunham et al. (2006) regarding the inadequacy of innovative community engagement frameworks that explore new combinations of factors that facilitate the relationship between the firm and the community.

3) SQ2. Subtheme. CSR contributed to creating shared value when a firm committed to CSR as a core value with the intent to meet the expectations of society in a collaborative process to help resolve often conflicting stakeholder views. These factors were suggested by the study interview data: CSR as a business core value, meeting the TBL expectations of society in a collaborative process, integrating company and community, and competitive advantage for the firm. Interviews with global leaders supported assertions that CSR as a core value of the firm demonstrates: (a) societal expectations of business have evolved to become rules of the game; (b) the firm must be accountable for non-shareholder interests; (c) and shareholders have moral obligations toward society (Schwartz \& Saiia, 2012). The interview data implicitly and explicitly supported the assertion that business is under increasing pressure to be accountable to society as well as shareholders (Freeman \& Hasnaoui, 2011; Maltz, Thomson, \& Ringold, 2011). The study data confirmed the emerging view that CSR is not whether but how business should be responsive to society's expectations (Abels \& Martelli, 2012; Maltz et al., 2011).

The responses of interviewed business leaders aligned with the four dimensions of CSR: improve profitability, meet social expectations, accomplish business goals, and behave ethically (Brown \& Forster, 2013). The study data supported Carroll (1998) and Schwartz and Saiia's (2012) contention that the social responsibility of business includes economic, social, and environmental expectations of society. The following objections to CSR were not mentioned by the interviewees: the construct intrudes on what should be the proper role of government, distracts from making a profit, and encourages unauthorized distribution of shareholder's money by management ("Does CSR Work?" 2008).

4) SQ3. Subtheme. The TBL contributed to creating shared value when applied as a holistic mindset using a dialogue process between business and watershed initiatives that demonstrated the value of the TBL construct to help resolve often conflicting stakeholder views. Factors supporting the sub theme: holistic mindset, dialogue, business leadership, demonstrating the value of the TBL. Sustainable development required integration of the TBL of economic prosperity, social equity, and environmental quality into the firm's strategic decision-making; however, the three dimensions are not always in harmony (Gao \& Zhang, 2006; Glavas \& Mish, 2015; Gomis, Parra, Hoffman \& McNulty, 2011). Interviews of business participants supported the integration of the TBL into strategic decision making but did not address compatibility. There was a consensus that TBL expertise should be shared with communities where the company has a presence.

The academic community was trending away from debating sustainable development as an if construct, while moving more toward improving understanding of why and how business is integrating the TBL (Glavas \& Mish, 2015). Study data confirmed the challenge for managers was to define the value of integrating the TBL in decisionmaking (Maltz, et al., 2011).

Watershed A (WSA) adopted the TBL in its mission statement but often found the primary challenge was identifying projects that met the TBL criteria. Watershed B (WSB) did not adopt the TBL in the organization's mission statement. There were multiple mentions in the interview data that the TBL construct was either not understood or was understood but not called the TBL.

Effectively integrating stakeholder dialogue in the firm's strategic decision-making was a critical factor in implementing the TBL (Gao \& Zhang, 2006). The study data confirmed dialogue was a critical factor in implementing the TBL. Dialogue has been widely advocated in the literature particularly as an instrument to facilitate the shift from conflict to collaboration in resolving TBL issues (Gao \& Zhang, 2006). The study data indicated the lack of dialogue was an implicit barrier between business and both WSA and WSB relating to participation and adoption of the TBL. Citizen advocacy was a primary justification for the firm to use dialogue processes as a method to resolve conflicting TBL issues (Nemetz, 2015). Study data confirmed WSA and WSB used citizen advocacy to focus public attention on their agendas. The effectiveness of dialogue processes varied depending on how closely a stakeholder group's agenda aligned with the agenda of WSA or WSB.

5) SQ4. Subtheme. A watershed initiative contributed to creating shared value using a collaborative approach to help resolve often conflicting stakeholder views when investing in projects that improved community quality of life economically, socially, and environmentally. Factors supporting the sub theme: a collaborative approach to develop a shared vision, improving community quality of life, applying the TBL. Often referred to as collaborative watershed initiative partnerships, the term was defined as multisector groups that worked together informally to 
address environmental issues within the boundary of a watershed (Benson, Jordan, Cook, \& Smith, 2013; Brinkman, Seekamp, Davenport, \& Brehm, 2012; Leach \& Pelkey, 2001). This definition was consistent with the organizational frameworks of WSA and WSB. A difference was the TBL was a primary factor in how WSA invested in projects.

Genskow (2009) and Benson et al. (2013) describe collaborative watershed initiative partnerships as focusing on specific geographical areas, emphasizing integration of economic, social and environmental resources (TBL), encouraging broad stakeholder participation, and bottom-up decision-making processes. This definition more closely aligned with WSA given the inclusion of TBL. The interview data supported the view that a strength of the watershed initiative was the diversity of participation that encouraged people to learn from each other by being around the same table in a collaborative process that built trust.

Leach and Pelkey's (2001) literature review of 36 watershed partnerships published between 1990 and 1999 found themes that accounted for success were adequate funding, effective leadership, a culture of trust, and motivated participants. These themes were confirmed by the data gathered from the study's 22 participants. An additional conclusion from the literature was frameworks that predict success were difficult to develop because community circumstances vary considerably (Leach \& Pelkey, 2001). This challenge was addressed by the versatility of the Sustainable Community Engagement Framework (Appendix A).

Common watershed initiative characteristics were: purposeful selection of participating stakeholders, a transparent process to build trust, clarity of decision-making, unbiased and competent facilitators, and adequate funding to support a viable process (Irvin \& Stansbury, 2004). These were operational characteristics of WSA and WSB.

Analysis of the interview data suggested a lack of alignment of the watershed initiative agenda with stakeholders other than environmental oriented groups was a weakness that needed to be addressed as the watershed initiative grew and evolved over time. Dias-Kope and Miller-Stevens (2015) emphasized that grassroots watershed initiatives were effective at building trust and social capital because stakeholders were part of the community. This assertion was confirmed from analysis of the interview data from WSA and WSB.

\section{Conclusions}

The research question was: How do shared value, CSR, TBL define a community engagement framework between the firm, the community, and U.S. watershed initiatives to help resolve often conflicting stakeholder views? The following principal conclusions addressed the research question:

- Shared value, CSR, TBL were factors that defined a community engagement framework when integrated into a collaborative strategy between the firm, the community, and U.S. watershed initiatives to help resolve often conflicting stakeholder views.

- Shared value factors were interrelated and contributed to creating shared value when strategically joined together in a Sustainable Community Engagement Framework (Appendix A) to help resolve often conflicting stakeholder views.

\subsection{Implications of the Findings}

This qualitative, multiple case study addresses a gap in the literature relating to unexplored engagement strategies that help resolve often conflicting stakeholder views between business and the communities where business has a presence.

1) The study conclusions redefined the business case for firms to participate in a collaborative dialogue process with watershed initiative partnerships in communities where the firm has a presence to help resolve often conflicting stakeholder views.

2) The factors of CSR and the TBL, when embedded in the firm's core values, help assure the success of a collaborative dialogue process with a watershed initiative partnership that may create shared value to help resolve often conflicting stakeholder views.

3) The shared value created for the firm from a collaborative dialogue process with a watershed initiative may improve community quality of life, enhance community relationships, assure the firm's license to operate and help resolve often conflicting stakeholder views.

4) The shared value for the watershed initiative in a collaborative process with business may be enhanced understanding and application of the TBL, improved community quality of life for projects that meet the TBL, a funding source for projects in addition to helping resolve often conflicting stakeholder views. 


\subsection{Recommendations for Action}

1) In communities where the firm has a business presence, an executive of the firm might consider leading a process, using the Sustainable Community Engagement Framework (Appendix A) as a resource, to determine whether there is a business case for participating in a collaborative dialogue with a watershed initiative.

2) The business case for participation in a collaborative dialogue process with a watershed initiative should demonstrate alignment with the firm's business interests.

3) The business case might be used as the basis for dialogue with the executive director of a watershed initiative to determine how well the agenda of the watershed initiative aligns with the business interests of the firm. A collaborative dialogue may define shared value for both organizations particularly in helping resolve often conflicting stakeholder views.

Further synthesis of the interview data indicated the following additional recommendations might facilitate watershed initiative relationships with business and other multisector community stakeholders. Implementation of the recommendations might also expand the watershed initiative's span of influence within watershed communities to improve quality of life for this and future generations.

1) Every 5 years, a watershed initiative might consider conducting a strategic planning process to develop objectives, goals, and plans for the next 5 years that reflect accomplishments and opportunities identified from the previous 5 years.

2) A goal of the watershed strategic planning process might be to consider conducting multi sector, regional workshops with the intent to enter into collaborative agreements or partnerships that accommodate the agendas of community sectors committed to improve community quality of life.

3) A goal of the watershed strategic planning process might be to consider improving business participation in the watershed initiative; for example, use existing business participants to reach out to community businesses to encourage participation by referencing the conclusions and recommendations of this research study including the Sustainable Community Engagement Framework (Appendix A).

4) A goal of the watershed strategic planning process might be to consider the TBL for inclusion as a component of the organization's vision and mission.

\subsection{Importance of the Study}

Using two watershed partnerships as examples, this qualitative, multiple case study redefines the business case for firms engaging their community stakeholders to resolve often conflicting views. The outcomes of this study are particularly relevant to academics, practitioners, business managers, and consultants engaged with high profile organizations whose business activity may generate community concerns about their business activities especially their environmental footprint. Examples are chemical, petroleum, pharmaceutical, agricultural, and utility businesses. The value of this study to business is new insight for engaging communities by applying the TBL to CSR engagement strategies. Potential outcomes, confirming Nemetz's (2015) view, are: business may gain competitive advantage, enhance reputation, demonstrate responsible citizenship, and avoid coercive regulations. Also, this study should be of interest to executive directors of NGO's, especially those organizations that have strong environmental orientations. The Sustainable Community Engagement Framework (see Appendix A) articulates the shared value created for both NGO's and business when they engage to improve community quality of life.

\subsection{Limitations}

Two limitations of this qualitative, multiple case study might have been (a) the scholarly nature of the research question and sub questions, and (b) the overall complexity of the constructs of CSR, TBL, and shared value.

The interviewees were preselected for their predicted knowledge and experience related to the research question and sub questions. However, the scholarly nature of the research question and sub questions required rewording the research question, and sub-questions in more generic form to be understandable to the interviewees. The rewording might have resulted in misinterpretation of the intent of the research question and sub questions. Responses to the interview questions might have included implicit or explicit bias or confusion due to varying degrees of understanding, experience, and knowledge of CSR, TBL, and shared value. There were multiple occasions when probing was required to achieve clarity of responses to the interview questions. Rewording of CSR, TBL, and shared value in generic language might have been inconsistent, confusing, or incompatible with the intent of the constructs.

Additional questions might be raised relating to the replication of the study findings particularly regarding 
inclusion of the TBL in the mission statement of WSA. A study finding was the inclusion of the TBL in the mission statement of WSA was an atypical factor compared to U.S. watershed initiatives. The uniqueness of the governance and organizational structure of WSA was an important study finding that deserves clearer understanding. Also, consistent with Yin's (2014) definition of a case study, there was no representative sample of participants from WSA or WSB.

\subsection{Recommendations for Future Research}

Future researchers should consider replicating the qualitative research design of this study to test the transferability of the findings. Additional qualitative research studies could improve understanding of what business sectors are the most likely candidates for participation in watershed initiatives. A study variable that could be explored to determine the variable's strategic importance is WSA included the TBL in WSA's mission statement while WSB did not include the TBL in their organization's mission statement. A limitation of the study was analysis of the research data indicated inconsistent understanding of the TBL as a construct for investing in watershed projects. Researchers might conduct a study to define criteria and a process for applying the TBL to projects supported by watershed initiatives. A common research method that might be appropriate is a mixed methods approach consisting of a survey of the study participants as the primary research method and then employing the qualitative focus group method to interpret and analyze the survey results (Hesse-Biber \& Leavy, 2017).

Future qualitative studies could explore the potential of applying the Sustainable Community Engagement Framework (Appendix A) in a global context particularly in European countries such as Denmark, Sweden, and the United Kingdom where sustainable development and the TBL have gained broader acceptance than in the United States.

\section{Concluding Statement}

The Sustainable Community Engagement Framework (see Appendix A) addressed a gap in the literature, and, at the same time, redefined the business case for business to broadly engage community stakeholders who influence or are influenced by a company's business activity. NGO's such as watershed initiatives are examples. This previously unexplored framework also has the potential to be applied globally to achieve high impact collaboration with multi sector stakeholder organizations that are strategic to a company's business success.

\section{References}

Abels, P. B., \& Martelli, J. T. (2012). What is CSR all about? Paper presented at the Global Conference on Business \& Finance Proceedings, Hilo: Institute for Business \& Finance Research, 7(2), 86-90. Retrieved from http://www.theibfr.com/conference.htm

Adler, P. S., \& Kwon, S. (2002). Social capital: Prospects for a new concept. Academy of Management Review, 27(1), 17-40. https://doi.org/10.5465/amr.2002.5922314

Barnham, C. (2015). Quantitative and qualitative research. International Journal of Market Research, 57(6), 837854. https://doi.org/10.2501/IJMR-2015-070

Benson, D., Jordan, A., Cook, H., \& Smith, L. (2013). Collaborative environmental governance: Are watershed partnerships swimming or are they sinking? Land Use Policy, 30, 748-757. https://doi.org/10.1016/j.landusepol.2012.05.016

Bowen, F., Newenham-Kahindi, A., \& Herremans, I. (2010). When suits meet roots: The antecedents and consequences of community engagement strategy. Journal of Business Ethics, 95, 297-318. https://doi.org/10.1007/s10551-009-0360-1

Bowie, N. E. (2012). Stakeholder theory: The state of the art. Business Ethics Quarterly, 22(1), 179-185. https://doi.org/10.5840/beq20122219

Bradley, K., Hauser, T., Koontz, M., \& Bruskotter, J. T. (2012). Volunteer participation in collaborative watershed partnerships: Insights from the theory of planned behavior. Journal of Environmental Planning and Management, 55(1), 77-94. https://doi.org/10.1080/09640568.2011.581535

Brinkman, E., Seekamp, E., Davenport, M. A., \& Brehm, J. M. (2012). Community capacity for watershed conservation: A quantitative assessment of indicators and core dimensions. Environmental Management, 50, 736-749. https://doi.org/10.1007/s00267-012-9922-6

Brown, J. A., \& Forster, W. R. (2013). CSR and stakeholder theory: A tale of Adam Smith. Journal of Business Ethics, 112(2), 301-312. https://doi.org/10.1007/s10551-012-1251-4

Burchell, J., \& Cook, J. (2013). Sleeping with the enemy? Strategic transformation in business-NGO relationships 
through stakeholder dialogue. Journal of Business Ethics, 113(3), 505-518. https://doi.org/10.1007/s10551012-1319-1

Carroll, A. B. (1998). The four faces of corporate citizenship. Business \& Society Review, 100(101), 1-7. https://doi.org/10.1111/0045-3609.00008

Carter, N., Bryant-Lukosius, D., Neville, A., \& DiCenso, A. (2014). The use of triangulation in qualitative research. Oncology Nursing Forum, 41(5), 545-547. https://doi.org/10.1188/14.ONF.545-547

Chiu, T., \& Wang, Y. (2015). Determinants of social disclosure quality in Taiwan: An application of stakeholder theory. Journal of Business Ethics, 129(2), 379-398. https://doi.org/10.1007/s10551-014-2160-5

Chong, D. (2013). The relevance of management to society: Peter Drucker's oeuvre from the 1940s and 1950s. Journal of Management History, 19(1), 55-72. https://doi.org/10.1108/17511341311286196

Cots, E. G. (2011). Stakeholder social capital: a new approach to stakeholder theory. Business Ethics: A European Review, 20(4), 328-341. https://doi.org/10.1111/j.1467-8608.2011.01635.x

Cramer, J. (2002). From financial to sustainable profit. Corporate Social Responsibility and Environmental Management, 9, 99-106. https://doi.org/10.1002/csr.12

Crane, A., Palazzo, G., Spence, L. J., \& Matten, D. (2014). Contesting the value of "creating shared value". California Management Review, 56(2), 130-153. https://doi.org/10.1525/cmr.2014.56.2.130

Dabic, T., \& Stojanov, Z. (2014). Techniques for collecting qualitative field data in education research: example of two studies in information technology filed. Singidunum Journal of Applied Sciences, 362-367. https://doi.org/10.15308/sinteza-2014-362-367

Dawkins, C. E. (2014). The principle of good faith: Toward substantive stakeholder engagement. Journal of Business Ethics, 121, 283-295. https://doi.org/10.1007/s10551-013-1697-z

Devenin, V., \& Bianchi, C. (2018). Soccer fields? What for? Effectiveness of corporate social responsibility initiatives in the mining industry. Corporate Social Responsibility and Environmental Management, 25, 866-879. https://doi.org/10.1002/csr.1503

Diaz-Kope, L., \& Miller-Stevens, K. (2015). Rethinking a typology of watershed partnerships: A governance perspective. Public Works management \& Policy, 20(1), 29-48. https://doi.org/10.1177/1087724X14524733

Does CSR work? (2008, January). The Economist, 8. Retrieved from http://www.economist.com

Dunham, L., Freeman, R. E., \& Liedtka, J. (2006). Enhancing stakeholder practice: A particularized exploration of community. Business Ethics Quarterly, 16(1), 23-42. https://doi.org/10.5840/beq20061611

Emerson, W. M., Alves, H., \& Raposo, M. (2011). Stakeholder theory: Issues to resolve. Management Decision, 49(2), 226-252. https://doi.org/10.1108/00251741111109133

FitzGerald, N., \& Cormack, M. (2006). The role of business in society. The Conference Board, Harvard University CSR Initiative \& International Business Leaders Forum. Paper presented at series of Leadership Dialogues sponsored by Clinton Global Initiative.

Freeman, I., \& Hasnaoui, A. (2011). The meaning of corporate social responsibility: The vision of four nations. Journal of Business Ethics, 100, 419-443. https://doi.org/10.1007/s10551-010-0688-6

Fusch, P. I., \& Ness, L. R. (2015). Are we there yet? Data saturation in qualitative research. The Qualitative Report, 20(9), 1408-1416. https://doi.org/10.46743/2160-3715/2015.2281

Gao, S. S., \& Zhang, J. J. (2006). Stakeholder engagement, social auditing and corporate sustainability. Business Process Management Journal, 12(6), 722-740. https://doi.org/10.1108/14637150610710891

Genskow, K. D. (2009). Catalyzing collaboration: Wisconsin's agency-initiated basin partnerships. Environmental Management, 43, 411-424. https://doi.org/10.1007/s00267-008-9236-x

Glavas, A., \& Mish, J. (2015). Resources and capabilities of the triple bottom line firms: Going over old or breaking ground? Journal of Business Ethics, 127(3), 623-642. https://doi.org/10.1007/s10551-014-2067-1

Golafshani, N. (2003). Understanding reliability and validity in qualitative research. The Qualitative Report, 8(4), 597-607. Retrieved from http://www.nova.edu

Gomis, A. J., Parra, M. G., \& Hoffman, W. M., McNulty, R. E. (2011). Rethinking the concept of sustainability. Business and Society Review, 116(2), 171-191. https://doi.org/10.1111/j.1467-8594.2011.00381.x

Hall, N. L., \& Jeanneret, T. (2015). Social licence to operate: An opportunity to enhance CSR for deeper 
communication and engagement. Corporate Communications: An International Journal, 20(2), 213-227. https://doi.org/10.1108/CCIJ-01-2014-0005

Harrison, J. S. (2013). Stakeholder theory, value and firm performance. Business Ethics Quarterly, 23(1), 97-124. https://doi.org/10.5840/beq20132314

Harrison, J. S., \& Wicks, A. C. (2013). Stakeholder theory, value and firm performance. Business Ethics Quarterly, 23(1), 97-124. https://doi.org/10.5840/beq20132314

Hesse-Biber, S. N., \& Leavy, P. (2011). The practice of qualitative research. Thousand Oaks, CA: SAGE Publications, Inc.

Howell, K. E. (2013). Reliability, generalization, and reflexivity: Identifying validity and trustworthiness. In An Introduction to the Philosophy of Methodology. https://doi.org/10.4135/9781473957633.n12

Irvin, R. A., \& Stansbury, J. (2004). Citizen participation in decision making: Is it worth the effort? Public Administration Review, 64(1), 55-65. https://doi.org/10.1111/j.1540-6210.2004.00346.x

Jensen, T., \& Sandstrom, J. (2013). In defence of stakeholder pragmatism. Journal of Business Ethics, 114, $225-$ 237. https://doi.org/10.1007/s10551-012-1338-y

Krishnan, V. S. (2011). In defense of social responsibility of business. Mustang Journal of Business and Ethics, 2, 31-37. Retrieved from http://mustangjournals.com

Krstovic, J., Bakic, T. V., \& Kostic, S. (2012). The role of business in the society. Management, 62, 67-72. https://doi.org/10.7595/management.fon.2012.0004

Leach, W. D., \& Pelkey, N. W. (2001). Making watershed partnerships work: A review of the empirical literature. Journal of Water Resources Planning \& Management, 127(6), 378-385. https://doi.org/10.1061/(ASCE)0733-9496(2001)127:6(378)

Leedy, P. D., \& Ormrod, J. E. (2016). Practical research planning and design. Upper Saddle River, NJ: Pearson Education Inc.

Liu, G., Eng, E., \& Ko, W. (2013). Strategic direction of corporate community involvement. Journal of Business Ethics, 115, 469-487. https://doi.org/10.1007/s10551-012-1418-z

Madrakhimova, F. S. (2013). Evolution of the concept and definition of corporate social responsibility. Paper presented at Global Conference on Business and Finance Proceedings, 8(2), 113-118. Retrieved from http://www.theibfr.com/proceedings.htm

Maltz, E., Thomson, F., \& Ringold, D. J. (2011). Assessing and maximizing corporate social initiatives: A strategic view of corporate social responsibility. Journal of Public Affairs, 11(4), 344-352. https://doi.org/10.1002/pa.384

McLennan, S., \& Banks, G. (2019). Reversing the lens: Why corporate social responsibility is not community development. Corporate Social Responsibility and Environmental Management, 26, 117-126. https://doi.org/10.1002/csr.1664

Moratis, L. (2014). ISO 26000. Journal of Corporate Citizenship, 53, 77-90. https://doi.org/10.9774/GLEAF.4700.2014.ma.00007

Nemetz, A. M. (2015). A global investigation of government and community stakeholder influences on large company engagement in sustainability. International Journal of Economics and Finance, 7(2), 1-14. https://doi.org/10.5539/ijbm.v10n2p1

Nwagbara, U., \& Reid, P. (2013). Corporate social responsibility and management trends: Changing times and changing strategies. Economic Insights: Trends and Challenges, 65(2), 12-19. Retrieved from http://www.upg-bulletin-se.ro

Orij, R. (2010). Corporate social disclosures in the context of national cultures and stakeholder theory. $\begin{array}{lllll}\text { Accounting, Auditing \& } \quad \text { Accountability } & \text { Journal, 23(7), }\end{array}$ https://doi.org/10.1108/09513571011080162

Padgett, D. K. (2012). Introduction. In Qualitative and Mixed Methods in Public Health, 1-29. Thousand Oaks, CA: SAGE Publications, Inc. https://doi.org/10.4135/9781483384511.n1

Parmar, B. L., Freeman, R. E., Harrison, J. S., Wicks, A. C., Purnell, L., \& deColle, S. (2010). Stakeholder theory: The state of the art. Academy of Management Annals, 4(1), 403-445. https://doi.org/10.5465/19416520.2010.495581 
Perrini, F., Russo, A., Tencati, A., \& Vurro (2011). Deconstructing the relationship between corporate social and financial performance. Journal of Business Ethics, 102, 59-76. https://doi.org/10.1007/s10551-011-11941

Porter, M. E., \& Kramer, M. R. (2011). Creating shared value. Harvard Business Review, 89(1/2), 62-77. Retrieved from http://hbr.org/magazine

Rangan, K., Chase, L., \& Karim, S. (2015). The truth about CSR. Harvard Business Review, 93(1/2), 40-49. Retrieved from http://hbr.org/magazine

Russo, A., \& Perrini, F. (2010). Investigating stakeholder theory and social capital: CSR in large firms and SMEs. Journal of Business Ethics, 91, 207-221. https://doi.org/10.1007/s10551-009-0079-z

Salmona, M., \& Kaczynski, D. (2016). Don't blame the software: Using qualitative data analysis software successfully in doctoral research. Qualitative Social Research, 17(3).

Schwartz, M. S., \& Saiia, D. (2012). Should firms go beyond profits? Milton Freeman versus broad CSR1. Business \& Society Review, 117(1), 1-31. https://doi.org/10.1111/j.1467-8594.2011.00397.x

Shank, G. D. (2006). Qualitative research: A personal skills approach. Upper Saddle River, N.J.: Pearson Education Inc.

Sloan, P. (2009). Redefining stakeholder engagement: From control to collaboration. Journal of Corporate Citizenship, 36, 25-40. https://doi.org/10.9774/GLEAF.4700.2009.wi.00005

Sonpar, K. (2011). Stakeholder theory: The state of the art. M@N@Gement, 14(3), 210-220. https://doi.org/10.3917/mana.143.0210

Spence, L. J., \& Schmidpeter, R. (2003). SMEs, social capital and the common good. Journal of Business Ethics, 45(1/2), 93-108. https://doi.org/10.1023/A:1024176613469

Stake, R. E. (1995). The art of case study research. Thousand Oaks, CA: SAGE Publications Inc.

Steurer, R. (2006). Mapping stakeholder theory anew: From stakeholder theory of the firm to three perspectives on business--society relations. Business Strategy \& the Environment, 15(1), 55-69. https://doi.org/10.1002/bse.467

Strand, R., Freeman, R., \& Hockerts, K. (2015). Corporate social responsibility and sustainability in Scandinavia. Journal of Business Ethics, 127(1), 1-15. https://doi.org/10.1007/s10551-014-2224-6

Tideman, S. G., Arts, M. C., \& Zandee, D.P. (2013). Sustainable leadership. Journal of Corporate Citizenship, 49. https://doi.org/10.9774/GLEAF.4700.2013.ma.00004

Toma, J. D. (2011). Approaching rigor in applied qualitative research. In C. F. Conrad, \& R. C. Serlin (Eds.), The SAGE Handbook for Research in Education: Pursuing Ideas in the Keystone of Exemplary Inquiry. https://doi.org/10.4135/9781483351377.n17

Vitolla, F., Raimo, N., Rubino, M., \& Garzoni, A. (2019). How pressure from stakeholders affects integrated reporting quality. Corporate Social Responsibility and Environmental Management, 26(6), 1591-1606. https://doi.org/10.1002/csr.1850

Vitolla, F., Raimo, N., Rubino, M., \& Garzoni, A. (2019). The impact of national culture on integrated reporting quality: A stakeholder approach. Business Strategy and the Environment, 28(8), 1558-1571. https://doi.org/10.1002/bse.2332

Warhurst, A. (2005). Future roles of business in society: The expanding boundaries of corporate responsibility and a compelling case for partnership. Futures, 37, 151-168. https://doi.org/10.1016/j.futures.2004.03.033

Williams, O. F. (2014). CSR: Will it change the world. Journal of Corporate Citizenship, 53, 9-26. https://doi.org/10.9774/GLEAF.4700.2014.ma.00004

Yin, R. K. (2014). Case study research design and methods. Thousand Oaks, CA: Sage Publications, Inc. 


\section{Appendix A. Sustainable Community Engagement Framework}

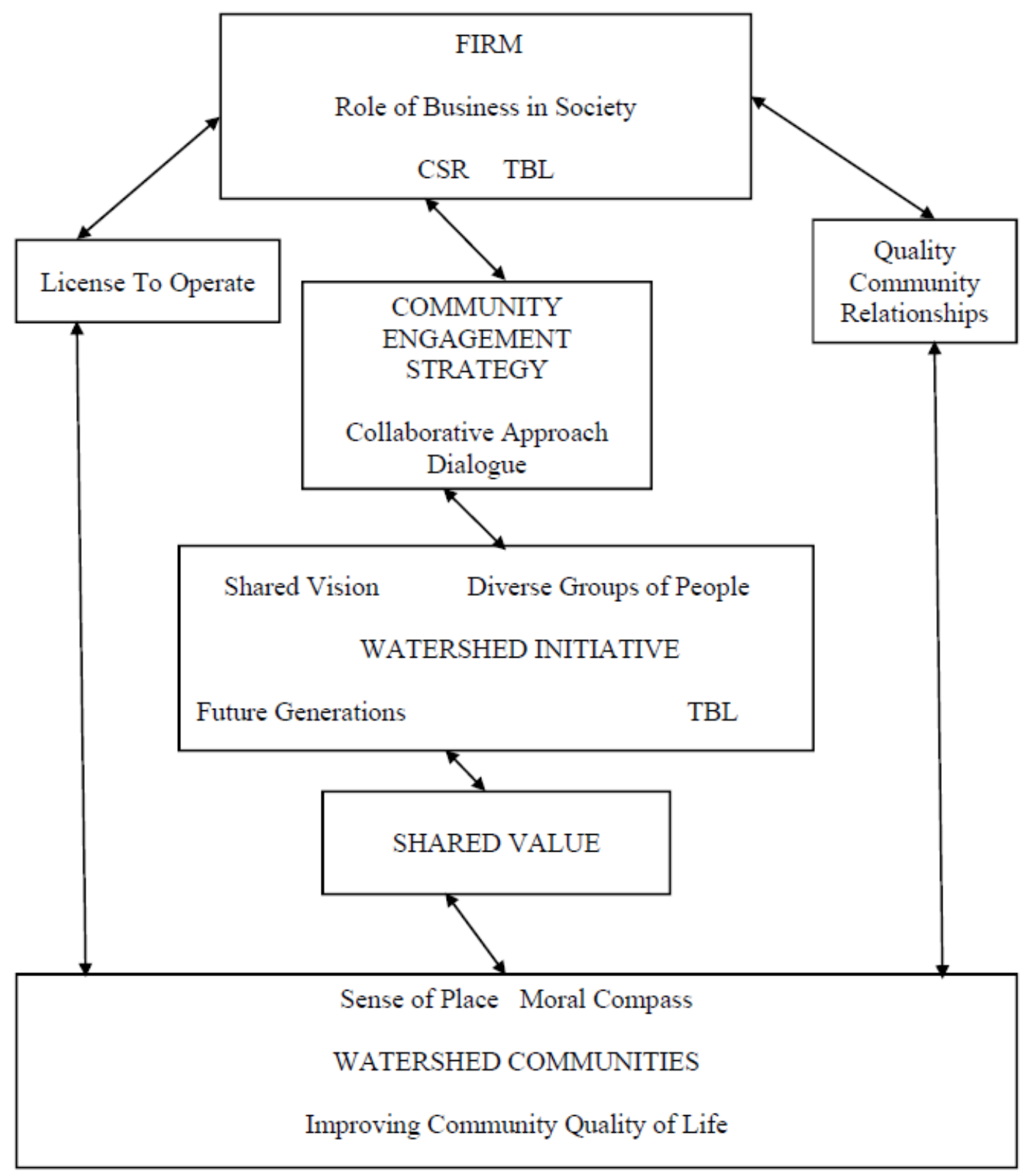

Note. According to the study data, shared value, CSR, the TBL are interrelated and when implemented in a strategy are factors that define an unexplored Sustainable Community Engagement Framework between the firm, the community, and U.S. watershed initiatives.

\section{Copyrights}

Copyright for this article is retained by the author(s), with first publication rights granted to the journal.

This is an open-access article distributed under the terms and conditions of the Creative Commons Attribution license (http://creativecommons.org/licenses/by/4.0/). 